\title{
Brucella abortus Induces a Warburg Shift in Host Metabolism That Is Linked to Enhanced Intracellular Survival of the Pathogen
}

\author{
Daniel M. Czyż, ${ }^{a, b}$ Jonathan W. Willett, ${ }^{a, b}$ Sean Crossona,b,c \\ Howard Taylor Ricketts Laboratory, University of Chicago, Argonne National Laboratory, Lemont, Illinois, USAa; \\ Department of Biochemistry and Molecular Biology, University of Chicago, Chicago, Illinois, USA b; Department \\ of Microbiology, University of Chicago, Chicago, Illinois, USA
}

ABSTRACT Intracellular bacterial pathogens exploit host cell resources to replicate and survive inside the host. Targeting these host systems is one promising approach to developing novel antimicrobials to treat intracellular infections. We show that human macrophage-like cells infected with Brucella abortus undergo a metabolic shift characterized by attenuated tricarboxylic acid cycle metabolism, reduced amino acid consumption, altered mitochondrial localization, and increased lactate production. This shift to an aerobic glycolytic state resembles the Warburg effect, a change in energy production that is well described in cancer cells and also occurs in activated inflammatory cells. B. abortus efficiently uses lactic acid as its sole carbon and energy source and requires the ability to metabolize lactate for normal survival in human macrophage-like cells. We demonstrate that chemical inhibitors of host glycolysis and lactate production do not affect in vitro growth of $B$. abortus in axenic culture but decrease its survival in the intracellular niche. Our data support a model in which infection shifts host metabolism to a Warburg-like state, and B. abortus uses this change in metabolism to promote intracellular survival. Pharmacological perturbation of these features of host cell metabolism may be a useful strategy to inhibit infection by intracellular pathogens.

IMPORTANCE Brucella spp. are intracellular bacterial pathogens that cause disease in a range of mammals, including livestock. Transmission from livestock to humans is common and can lead to chronic human disease. Human macrophage-like cells infected with Brucella abortus undergo a Warburg-like metabolic shift to an aerobic glycolytic state where the host cells produce lactic acid and have reduced amino acid catabolism. We provide evidence that the pathogen can exploit this change in host metabolism to support growth and survival in the intracellular niche. Drugs that inhibit this shift in host cell metabolism inhibit intracellular replication and decrease the survival of $B$. abortus in an in vitro infection model; these drugs may be broadly useful therapeutics for intracellular infections.

KEYWORDS infection, Warburg effect, lactate, therapeutics, antimetabolite drug, 3-bromopyruvic acid, NHI-2, 2-deoxy-D-glucose, brucellosis, antibiotic, metabolism, zoonotic infection

Mastan acrophages can be activated by pathogen-associated proinflammatory molecules, such as lipopolysaccharide (LPS). Classically activated (i.e., M1) macrophages undergo a major metabolic shift in which the tricarboxylic acid (TCA) cycle is downregulated, and energy production transitions from oxidative phosphorylation to the less efficient process of aerobic glycolysis $(1,2)$. This change in metabolism, known as the Warburg effect (3), is a well-described metabolic feature of cancer cells (4).
Received 27 March 2017 Accepted 18 May 2017

Accepted manuscript posted online 30 May 2017

Citation Czyż DM, Willett JW, Crosson S. 2017. Brucella abortus induces a Warburg shift in host metabolism that is linked to enhanced intracellular survival of the pathogen. J Bacteriol 199:e00227-17. https://doi.org/10 .1128/JB.00227-17.

Editor George O'Toole, Geisel School of Medicine at Dartmouth

Copyright $\odot 2017$ American Society for Microbiology. All Rights Reserved.

Address correspondence to Sean Crosson, scrosson@uchicago.edu. 
Increased glucose consumption through glycolysis is thought to increase ATP levels; a corresponding increase in pentose phosphate pathway activity generates NADP (NADPH), which is subsequently used by NADPH oxidases to generate reactive oxygen species (ROS) (5). This metabolic shift enables cells to launch general antimicrobial defenses by increasing the concentrations of ROS and reactive nitrogen intermediates (6).

The intracellular pathogen Brucella abortus invades host cells and is trafficked to a compartment known as the Brucella-containing vacuole, where it replicates. To successfully find its way to this niche, $B$. abortus must avoid numerous chemical insults by the host cell and adapt to the nutrient resources available within host cells. The mechanisms by which $B$. abortus evades host defenses and takes advantage of host metabolic responses remain unclear, but previous work showed that $B$. abortus induces a Warburg-like metabolic shift in mammalian host cells. We characterize this host metabolic shift and provide evidence that it is advantageous for $B$. abortus survival in the intracellular niche. We further demonstrate that chemical inhibition of Warburg metabolism attenuates $B$. abortus survival in cultured macrophage-like host cells. Our study informs a model in which $B$. abortus exploits an innate immune metabolic response to support infection.

\section{RESULTS}

Brucella abortus infection of human macrophage-like cells disrupts mitochondrial function and localization. To characterize the effect of intracellular colonization by $B$. abortus on human cell metabolism, we employed mammalian cell Phenotype MicroArrays (Biolog) to measure respiration in terminally differentiated metabolically active THP-1 cells. These cells were cultivated in minimal essential medium in the presence of central metabolic substrates specifically selected to measure mitochondrial function. Three of the substrates, $\alpha$-ketoglutaric acid, $\beta$-hydroxybutyric acid, and pyruvic acid, are metabolized in mitochondria. We assessed the respiration of cultured human cells utilizing only the provided substrate as a primary energy source by using a colorimetric assay that measures the reduction of a redox indicator dye. This assay allowed us to assess the cells' ability to metabolize substrates across different molecular pathways and thus provided a measurement of metabolic pathway function upon infection (Fig. 1A). We infected the cells with B. abortus at increasing multiplicities of infection (MOI). To eliminate the possibility that Brucella-induced cell death caused the changes in the metabolic activity of the human cells, we removed medium containing mitochondrial substrates, replaced it with regular growth medium containing glucose, and assessed cell viability using an MTT [3-(4,5-dimethylthiazol-2-yl)-2,5-diphenyltetrazolium bromide] dye reduction assay. The number of viable cells was statistically equivalent at different Brucella MOI (Fig. 1B). Uninfected cells utilized all of the mitochondrial substrates (Fig. 1C), but the ability to utilize these substrates decreased in cells infected with $B$. abortus (Fig. 1D). This decrease was dependent on the MOI (Fig. 1A). Infected and uninfected THP-1 cells were incubated in equivalent media containing gentamicin, and thus we attribute the observed metabolic effect to $B$. abortus infection and not to a component of the culture medium. B. abortus-infected cells continued to utilize glucose, in contrast to the other substrates (Fig. 1C and D). In fact, glucose consumption by infected THP-1 cells increased with increasing MOI (Fig. 1E and F).

The marked inhibition of mitochondrial substrate utilization suggests that intracellular brucellae disrupt mitochondrial function. Parasites (7), viruses (8), and intracellular bacterial pathogens, including Brucella melitensis (9) and Listeria monocytogenes (10), perturb mitochondrial function in host cells. To obtain additional evidence that mitochondrial function is disrupted during $B$. abortus infection, we stained uninfected and infected cells with a dye specific for mitochondria. The flatter morphology of HeLa cells (compared with THP-1 cells) permitted clearer visualization of mitochondria on our microscopy setup in biosafety level 3 (BSL-3) containment, so we used HeLa cells for this assay. Disruptions of overall cell morphology and mitochondrial localization were 
A

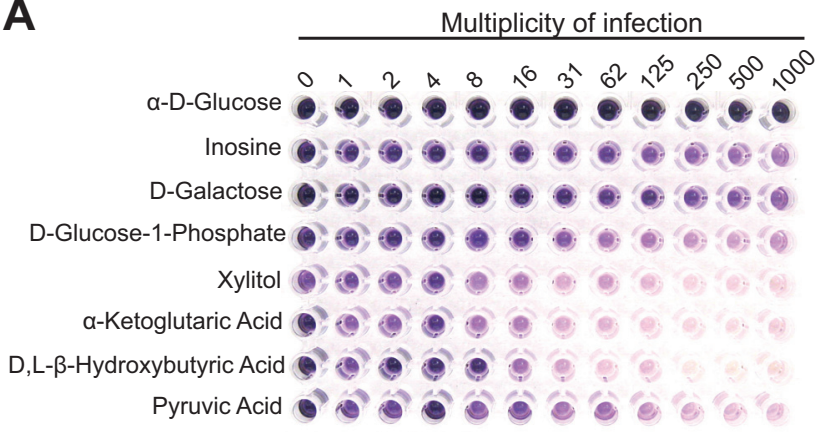

C

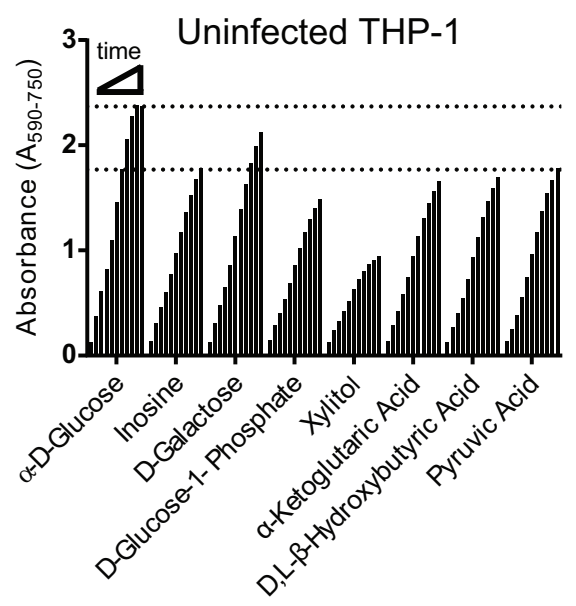

E

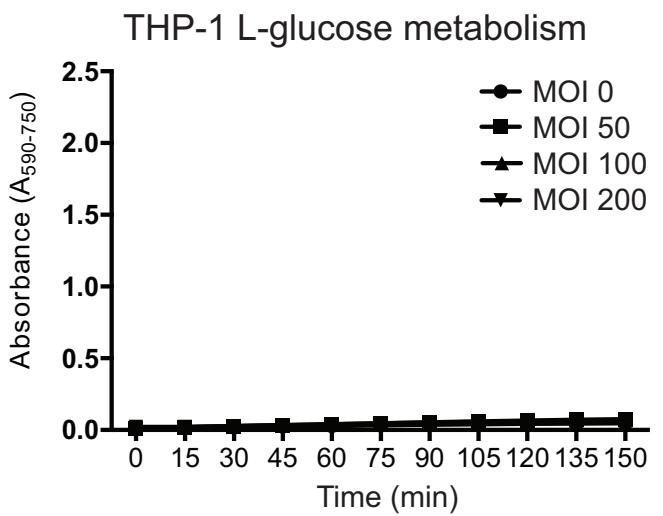

B

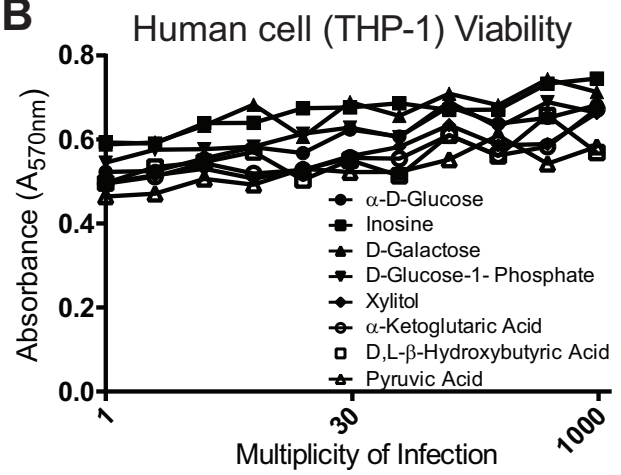

D

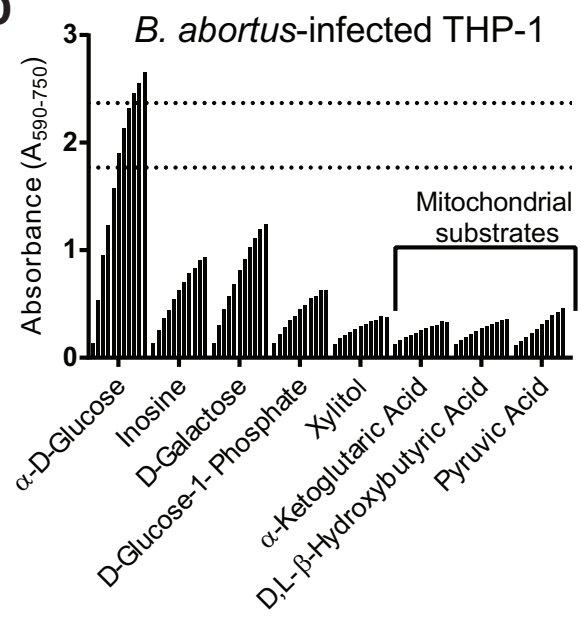

F

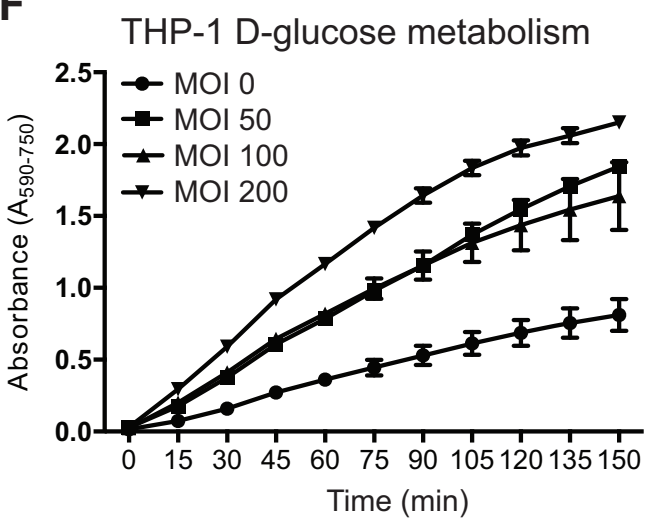

FIG 1 Mitochondrial function is perturbed in THP-1 cells infected with B. abortus. (A) Mammalian Phenotype MicroArray plate designed to measure mitochondrial function. The ability of THP-1 cells infected with B. abortus at increasing multiplicity of infection (MOI) to utilize metabolic substrates was assessed by measuring the reduction of a tetrazolium dye (see Materials and Methods). (B) An MTT cell viability assay was performed in the presence of glucose to assess the effect of $B$. abortus infection on human cell survival at the conclusion of the mammalian Phenotype MicroArray assay. (C and D) Dye reduction by uninfected and Brucella-infected (MOI, 125) human cells measured as a time-dependent absorbance readout. Cells were cultured in minimal medium supplemented either with glucose (control) or central metabolic substrates. Brackets indicate substrates ( $\alpha$-ketoglutaric acid, $\beta$-hydroxybutyric acid, and pyruvic acid) that enter the mitochondria, thereby providing a readout of mitochondrial function. Bars along the $x$ axes represent time (0 to 150 min) in 15 -min increments. Dotted lines mark the highest reading for utilization of glucose and pyruvic acid in uninfected THP-1 cells. (E and F) Metabolic activity of THP-1 in the presence of L-glucose (E) and D-glucose (F) at increasing B. abortus MOI as monitored by a colorimetric dye reduction assay. Error bars represent standard deviation $(n=3)$.

observed in HeLa cells with detectable B. abortus, whereas uninfected cells in the same field of view had normal cell morphology and mitochondrial staining patterns (Fig. 2). We do not attribute these changes in mitochondrial staining patterns to gentamicin in the culture medium, as mitochondria were indistinguishable from a control culture 


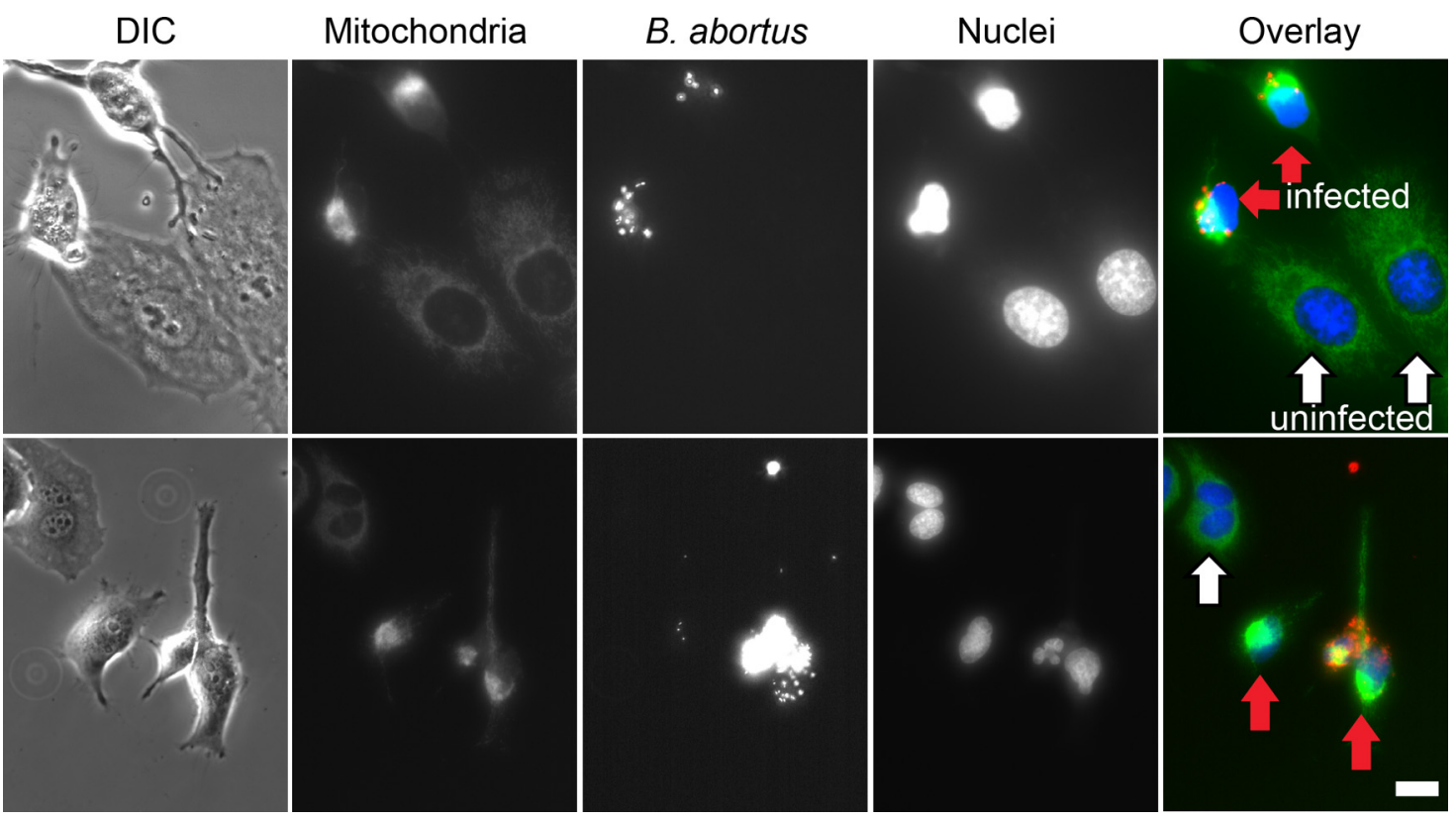

FIG 2 Intracellular B. abortus induces morphological changes of mitochondria localization in HeLa cells. Two fields showing mitochondrial staining (MitoTracker, green), B. abortus-Tn7mCherry (mCherry fluorescence, red), nuclei (Hoechst stain, blue), and the corresponding image with differential interference contrast (DIC) microscopy. Red arrows indicate cells with visible intracellular $B$. abortus, and white arrows indicate cells for which no infection is evident. Cells not infected with $B$. abortus have typical mitochondrial staining patterns (also see Fig. S1). Scale bar, $50 \mu \mathrm{m}$.

lacking gentamicin at concentrations up to $200 \mu \mathrm{g} \cdot \mathrm{ml}^{-1}$ (see Fig. S1 in the supplemental material). Although infected cells had a more rounded morphology in some cases, an MTT [3-(4.5-dimethylthiazol-2-yl)-2.5-diphenyltetrazolium bromide] cell viability assay revealed no loss of host cell viability with increasing $B$. abortus $\mathrm{MOI}$ within the same time frame (Fig. 1B). Therefore, it is unlikely that the changes in cell morphology and mitochondrial localization observed by fluorescence microscopy are a result of host cell death upon infection.

Most amino acids can be metabolized to enter the TCA cycle through anaplerotic reactions (11). To determine whether the observed $B$. abortus-mediated disruption of host mitochondrial function directly affects amino acid metabolism, we assessed the effect of infection on the host's ability to utilize amino acids as a carbon source. While glucose metabolism was unaffected, infected cells could not metabolize any of the amino acids known to enter the TCA cycle (Fig. 3). Together, the results of these experiments are consistent with a model in which infection of human cells with $B$. abortus results in major metabolic changes that are linked to perturbation of mitochondrial function.

Brucella-dependent induction of lactic acid production in human cells. Macrophages and dendritic cells have central functions in innate immunity. Upon activation, they can undergo a shift in energy metabolism by shutting down oxidative phosphorylation and increasing the rate of aerobic glycolysis in a process known as the Warburg effect (3). One hallmark of this effect is the production of lactic acid in the presence of oxygen. A previous study noted an increase in lactate production in nonpolarized macrophages infected with Brucella spp. (12). To test whether THP-1 cells infected with B. abortus shift their metabolism toward a Warburg-like state, we measured the production of lactic acid by infected cells and found that in THP-1 cells, lactic acid production increased with increasing $\mathrm{MOI}$ (Fig. 4A). To test whether this metabolic shift required infection with live $B$. abortus, we measured lactate production by THP-1 cells exposed to heat-killed B. abortus. Heat-killed Brucella spp. induced similar lactate production from the THP-1 human cell line, although at the highest MOI, the THP-1 cells treated with heat-killed pathogen produced less lactate than cells infected with live 


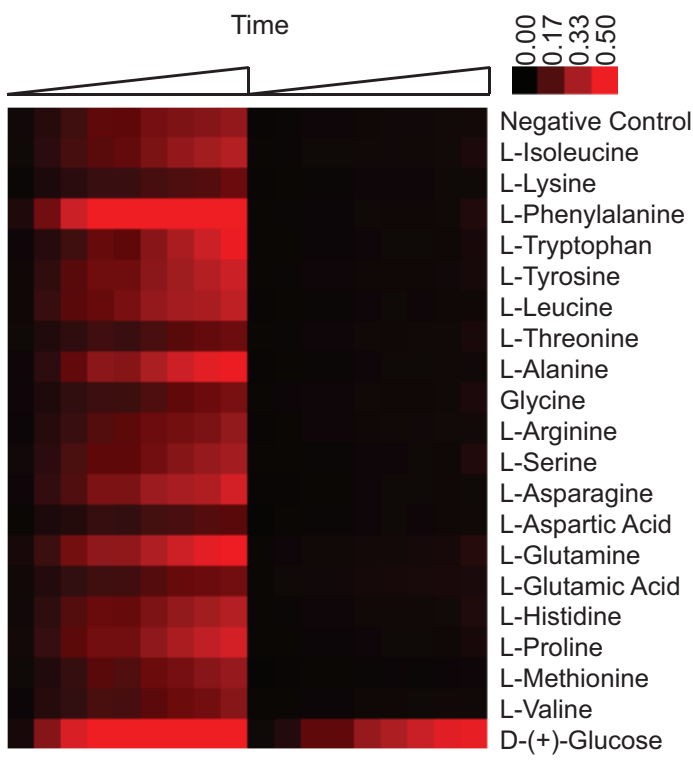

FIG 3 Host cell utilization of amino acids as a carbon source before and after B. abortus infection. The heat map represents host cell metabolism as measured colorimetrically via a redox dye (see Materials and Methods). Time-dependent metabolic change of noninfected (left) versus B. abortus-infected (right) THP-1 cells in the presence of amino acids is shown. Color is an arbitrary scale from black (no reduction of the dye, 0.00 ) to red (maximum reduction of the dye, 0.50 ). THP-1 has low metabolic activity in the Phenotypic MicroArray (PM) panel negative control, which is presumed to be due to utilization of a component(s) of fetal bovine serum. Addition of B. abortus inhibits THP-1 metabolism under this condition and in all assayed amino acids but not in glucose ( $B$. abortus $\mathrm{MOI}$ dependence of host glucose metabolism is depicted in Fig. 1F).

pathogen (Fig. 4B). These results, together with the data presented in Fig. 1 to 3 , support a model in which a molecular component of the $B$. abortus cell promotes a Warburg-like shift in host cell metabolism by disrupting mitochondrial function.

Brucella abortus requires lactate dehydrogenase for normal intracellular survival in THP-1 cells. Brucella and Salmonella spp. both replicate intracellularly and can persist in the host for long periods by shifting host metabolism to increase the available glucose (12-14). We measured B. abortus growth in axenic culture on lactic acid compared with that with three substrates that it can efficiently metabolize: L-glutamic acid, glucose, and erythritol. We found that $B$. abortus grows on lactic acid as the sole carbon and energy source as well as it does on glutamic acid, glucose, or erythritol

A Brucella induced lactate production

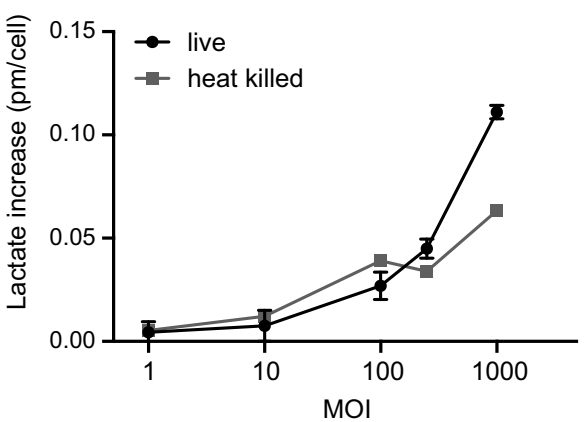

\section{B B. abortus axenic metabolism}

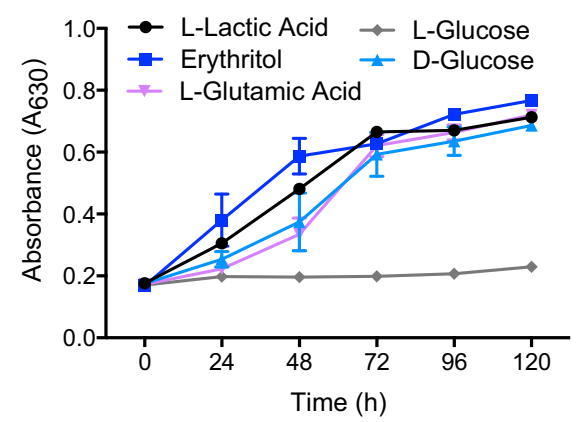

FIG 4 B. abortus induces host cell lactate production and utilizes lactate as a carbon and energy source as efficiently as glucose, erythritol, and glutamate. (A) Lactate level increase in B. abortus-infected THP-1 cells relative to the uninfected control at increasing MOI. (B) Metabolism of B. abortus measured on carbon/ energy sources L-lactate, L-glutamate, erythritol, D-glucose, and L-glucose in standing culture on Biolog plates. Data show an average of results from two independent experiments \pm standard deviation. 


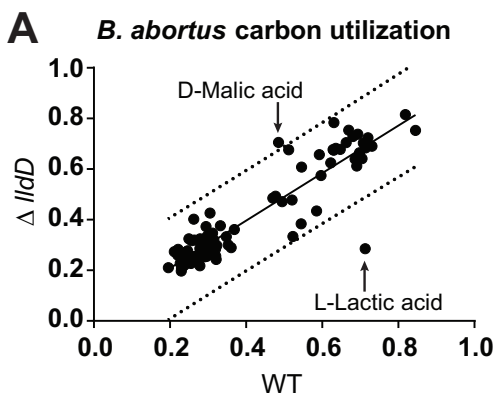

\section{B. abortus glucose medium}

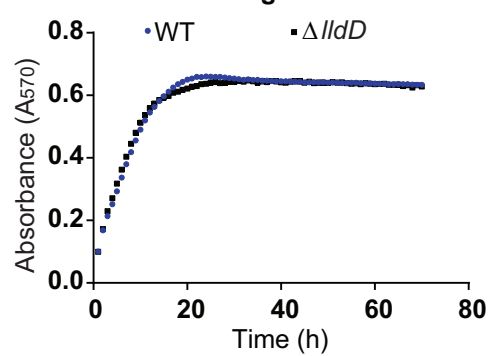

B

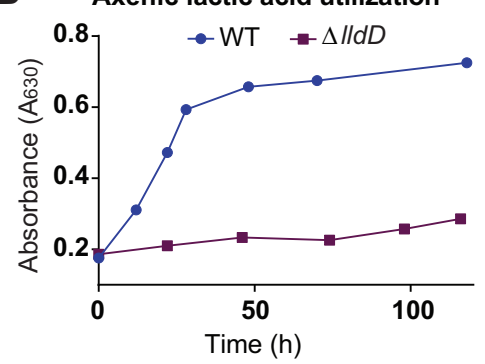

D Intracellular B. abortus

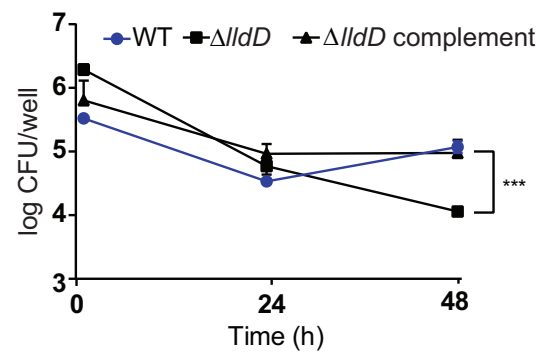

FIG 5 The $B$. abortus L-lactate dehydrogenase $\Delta / l d D$ mutant strain cannot utilize lactic acid as a sole carbon and energy source in axenic culture and is attenuated in a macrophage infection model. (A) Phenotype MicroArray carbon utilization measurements of wild-type (WT) B. abortus and L-lactate dehydrogenase $(\mathrm{LDH})$ mutant $(\Delta / / d D)$ strains. Metabolic activities for growth on 95 distinct carbon substrates (see Materials and Methods) are plotted against each other; the dotted line marks a $99 \%$ prediction band of a linear regression. Correlation values above the line represent a gain-of-function phenotype, and values below the line represent a loss-of-function phenotype. L-Lactic acid and D-malic acid are marked as loss-of-function and gain-of-function, respectively. (B) Graph representing timedependent utilization of lactic acid as a carbon and energy source in standing culture, measured by a metabolic indicator dye (see Materials and Methods). (C) Graph representing axenic growth of the WT and $\Delta / I d D$ mutant strains in glucose-containing Brucella broth. (D) Intracellular replication and survival of the WT and $\Delta / l d D$ mutant strains in a THP-1 macrophage cell infection model. Intracellular B. abortus was quantified as $\log _{10}$ CFU per well at 1, 24, and $48 \mathrm{~h}$ postinfection. Error bars represent standard deviation $(n=3) .{ }^{* *}, P<0.001$ (one-way ANOVA).

(Fig. 4B). We postulated that during infection, B. abortus may exploit the Warburg-type shift in host metabolism by utilizing lactic acid as a carbon and energy source.

To further assay B. abortus lactic acid metabolism, we engineered a strain harboring an in-frame deletion of the gene encoding L-lactate dehydrogenase (LDH), bab2_0315 $(\Delta / l d D)$. To determine whether the deletion of IIdD affects utilization of other carbon sources, we used Phenotype MicroArrays (Biolog) to compare the metabolic activity of the $\Delta / I D$ mutant to the wild type and found that utilization of L-lactic acid was the most statistically significant loss-of-function phenotype (Fig. 5A). The wild-type $B$. abortus exhibited robust growth on lactic acid as a carbon and energy source, but $B$. abortus $\Delta / l d D$ did not grow on lactic acid (Fig. 5B). The $\Delta / l d D$ mutant had no apparent growth defect in Brucella broth supplemented with glucose (Fig. 5C), but the numbers of CFU of the $\triangle / I d D$ mutant were significantly reduced in THP-1 macrophages relative to the wild type at the 48-h time point (Fig. 5D). Complementation of the mutation by the introduction of $I / d D$ at its native locus rescued the THP-1 replication/survival defect. Together, our results indicate that upon infection, human cells undergo a metabolic shift that results in increased lactate production. The lactate catabolic enzyme LDH is required for normal intracellular $B$. abortus replication and/or survival in an in vitro macrophage infection model.

Small-molecule glycolysis inhibitors decrease intracellular replication of Brucella abortus but do not affect axenic growth. The identification of pathogeninduced changes in host metabolism offers new avenues for the development of anti-infectives. Since Brucella-infected cells have disrupted mitochondrial metabolism and increased glycolysis, we used small-molecule inhibitors of glucose metabolism 
(Fig. 6A) to determine whether inhibition of the host glycolytic pathway and lactate production affected intracellular replication/survival of $B$. abortus. We tested 3-bromopyruvic acid (3-BPA), a potent glycolytic inhibitor (15, 16); methyl 1-hydroxy-6-phenyl-4-(trifluoromethyl)-1H-indole-2-carboxylate (NHI-2), an inhibitor of lactate dehydrogenase A (LDH-A) (17); and 2-deoxy-D-glucose (2-dG), a nonmetabolizable analog of D-glucose (18). We counted B. abortus cells located inside THP-1 cells treated with each of these antimetabolic compounds at various concentrations and expressed the results as the number of Brucella per THP-1 nucleus. Fluorescent Brucella puncta were often larger than a single B. abortus cell, particularly in untreated cells, and likely contained multiple bacteria. Nonetheless, we took a conservative approach and counted each fluorescent $B$. abortus spot as one cell. Each antimetabolic drug significantly inhibited the replication/survival of intracellular Brucella in live cells (Fig. 6B). This effect was particularly evident when drug-treated and untreated cells were visualized by fluorescence microscopy (Fig. $6 \mathrm{E})$.

To determine whether the antimicrobial activities of these compounds coincide with their cytotoxicity to human cells, we assessed their cytotoxicity using an XTT [2,3-bis(2-methoxy-4-nitro-5-sulfophenyl)-2H-tetra-5-carboxanilide] cell viability assay. As expected, each metabolic inhibitor was cytotoxic at high concentrations (Fig. 6C). However, treatment of THP-1 cells with 3-BPA, the most potent compound, inhibited $B$. abortus intracellular replication/survival at concentrations that were well below the THP-1 cytotoxicity threshold. NHI-2 and 2-dG were less potent but effectively inhibited replication/survival of intracellular Brucella organisms (Fig. 6B and C). Both 3-BPA and $\mathrm{NHI}-2$ significantly inhibited intracellular Brucella organisms at concentrations below the cytotoxicity threshold.

Finally, to determine whether the antimicrobial effect of these compounds occurs by targeting host metabolism or whether they also directly inhibit bacterial growth, we measured the growth and viability of $B$. abortus in axenic culture in the presence of 3-BPA, NHI-2, and 2-dG. Neither 3-BPA nor NHI-2 affected growth and viability of Brucella in axenic medium, although 2-dG had an inhibitory effect on axenic $B$. abortus growth at higher concentrations ( $\geq 100 \mathrm{mM}$ ).

These data support a model in which inhibition of host glycolysis and lactate production with 3-BPA and NHI-2 inhibits intracellular B. abortus replication/survival without directly targeting $B$. abortus growth (Fig. 6D). Together, these results demonstrate that infection-induced changes in host central metabolic pathways are required for proper replication/survival of intracellular B. abortus. Inhibition of the glycolytic pathway with host-targeting antimetabolic drugs may provide an effective means to decrease intracellular bacterial load without directly targeting the bacterium (Fig. 6E).

\section{DISCUSSION}

We have identified large metabolic changes in THP-1 host cells that occur upon exposure to the intracellular bacterial pathogen B. abortus. Intracellular B. abortus clearly perturbs the function of host mitochondria, as characterized by relocalized mitochondrial staining and the loss of the ability to utilize mitochondrial substrates (Fig. 1 and 2). The host metabolic effects we observed upon B. abortus infection resemble the effect of mitochondrial inhibitors (19) and are consistent with the previously reported downregulation of mitochondrion-associated gene expression in macrophages infected with $B$. melitensis (20). Many bacteria are known to affect host mitochondria (21), but only a few species have been reported to disrupt mitochondrial structure or localization $(9,10,22)$. The mitochondrial staining profile of infected cells observed in our study resembles that of cells treated with uncouplers in combination with a respiration inhibitor; although this treatment results in energy deprivation and aggregation of mitochondria, cells remained viable in this assay (23).

Intracellular pathogens compete with host cells for available nutrients, including central metabolites and amino acids (24). Human THP-1 cells utilize amino acids as an energy source, but this is inhibited by $B$. abortus infection (Fig. 3). The reduced ability 
A

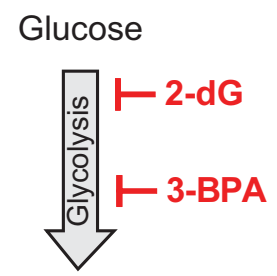

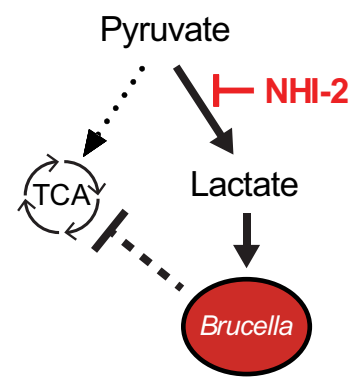

E
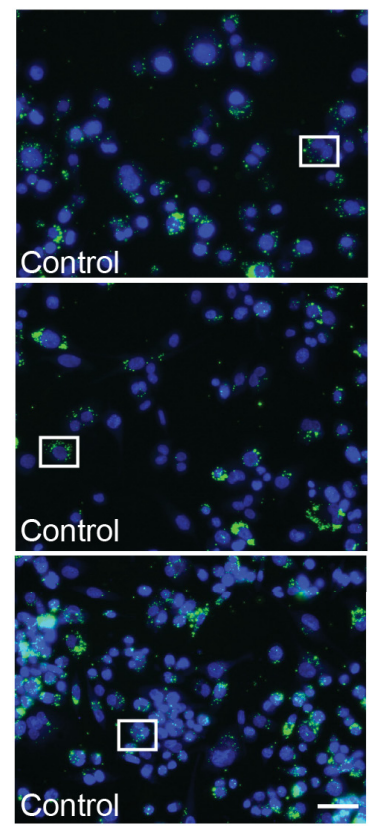

B

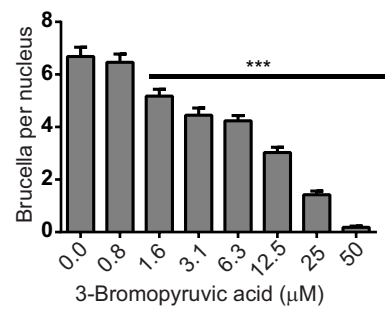

C

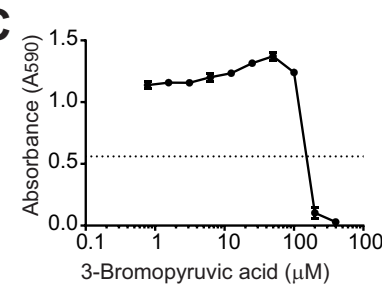

D

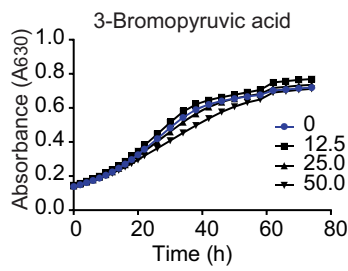

Intracellular B. abortus

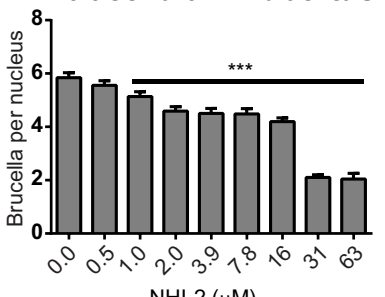

$\mathrm{NHI}-2(\mu \mathrm{M})$
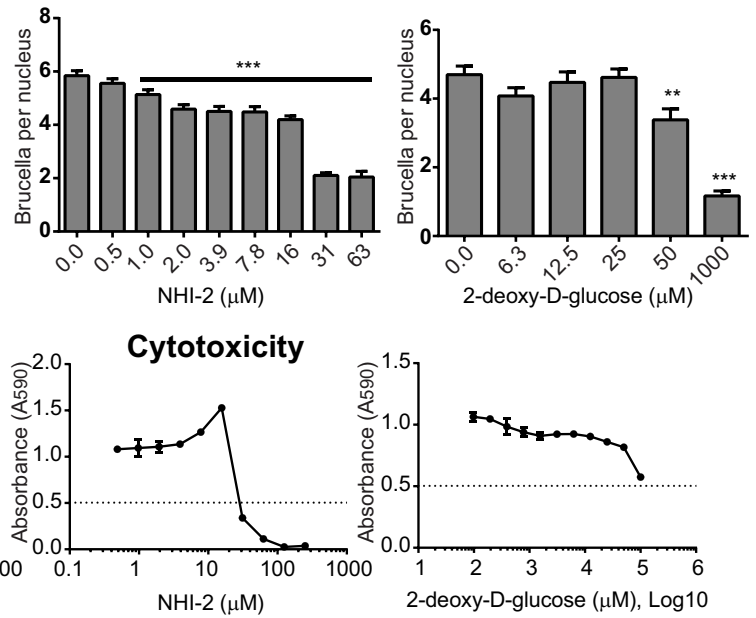

Brucella Axenic Growth
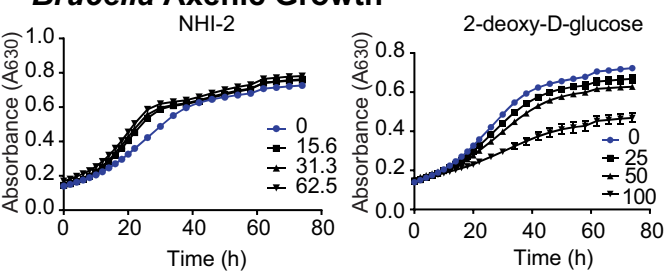

FIG 6 Pharmacological disruption of the host glycolytic pathway and lactate production inhibits replication of intracellular B. abortus. (A) Model depicting Brucella-dependent modulation of carbon metabolism and activation of aerobic glycolysis, resulting in the production of lactate. B. abortus utilizes lactate as efficiently as preferred substrates glucose and erythritol. Pharmacological inhibitors of glycolysis, 3-bromopyruvic acid (3-BPA), NHI-2, and 2-deoxy-D-glucose (2-dG) inhibit intracellular growth of B. abortus. (B) Graphs represent the effects of 3-BPA, NHI-2, and 2-dG on intracellular replication of B. abortus, as quantified by enumerating fluorescent bacteria per THP-1 nucleus; the effect of antiglycolytic compounds on infection was assessed by measuring the average ratio of bacteria to nuclei in THP-1 cells treated with each of the compounds. Statistical significance was evaluated from four biological replicates (10 images each) using one-way analysis of variance (ANOVA), followed by Dunnett's posttest ( ${ }^{* *}, P<0.01 ;{ }^{* * *}, P<0.001$ ). Error bars represent standard deviation from the mean. (C) Cytotoxicity of inhibitory compounds to THP-1 cells; an XTT assay was used to measure compound cytotoxicity to THP-1 cells. Dotted lines indicate the half-maximal inhibitory concentration $\left(I_{50}\right)$. (D) Effect of metabolic inhibitors on $B$. abortus axenic growth/metabolism in axenic culture. Brucella growth/metabolism was assayed by measuring tetrazolium-based dye reduction at $630 \mathrm{~nm}$. (E) Fluorescence images of nuclei (blue) and intracellular B. abortus (pseudocolored green) reflect the efficacy of 3-BPA, NHI-2, and 2-dG to inhibit B. abortus replication in the intracellular niche. Scale bars $=10 \mu \mathrm{m}$ (full view) and $50 \mu \mathrm{m}$ (magnified insets, marked with white box in full view). 
of infected host cells to utilize amino acids suggests a model whereby intracellular $B$. abortus competes for these substrates early in infection by diverting the host's metabolism away from amino acid consumption. This model is consistent with proteomic data showing downregulation of carbohydrate catabolic proteins and enhanced expression of enzymes involved in amino acid catabolism several hours after macrophage infection (25). Our data are also congruent with a recent model from Zúñiga-Ripa and colleagues (26) based on genetic analyses of $B$. abortus metabolic mutants. Data from these investigators suggest that pentose and hexose sugars are limited in the host and that energy is compensated by amino acids in certain infection niches.

In addition to our investigation of shifts in host amino acid metabolism upon infection, we also explored the induction of host lactate production upon exposure to B. abortus. Erythritol, glutamic acid, and glucose are efficiently metabolized by Brucella $(27,28)$, and our results show that, in axenic culture, B. abortus strain 2308 can metabolize lactate as the sole carbon and energy source as efficiently as these substrates (Fig. 4). Our data are thus consistent with a study from Gerhardt and Wilson reporting that lactate can be utilized as a carbon and energy source by Brucella abortus strain 19 (29), although the level of growth we observed for strain 2308 in the defined Phenotype MicroArray-lactate medium was significantly higher than that observed in this early report. Brucella spp. may take advantage of host lactate as an energy source in niches where lactate is naturally abundant, such as the placenta (30) or male reproductive tissue (31). Both lactate and amino acids have been proposed to provide energy to certain intracellular pathogens within the host environment (32). Brucella species pathogens have a tropism for genital organs, and the possibility that lactate serves as an important metabolic substrate for Brucella spp. during colonization of the reproductive tract has been recently reviewed by Letesson and colleagues (33).

Our observations that $B$. abortus (i) efficiently metabolizes lactate as a carbon and energy source and (ii) that THP-1 host cells exposed to B. abortus increase glucose consumption and lactate production raise the possibility that Brucella spp. take direct advantage of a Warburg-like shift in host inflammatory cells to support growth during infection. We took two approaches to test whether host lactate affects intracellular growth and/or survival in THP-1 macrophages. First, we created a $B$. abortus lactate dehydrogenase knockout $\Delta / I d D$ mutant strain which cannot utilize lactate in axenic culture (Fig. $5 \mathrm{~A}$ and $\mathrm{B}$ ). The $\Delta / I d D$ mutant showed no growth defects across a range of axenic media, but its intracellular replication/survival was attenuated by $\approx 1$ log after 48 $\mathrm{h}$ in host THP-1 cells (Fig. 5D). This provides evidence that the ability to utilize lactate is necessary for survival in the intracellular niche in the THP-1 model. In a second approach, we targeted host lactate synthesis using the small molecules NHI-2, 3-BPA, and 2-dG, which decrease lactate levels and inhibit aerobic glycolysis (17, 34, 35). Each of these metabolic inhibitors decreased intracellular growth and/or replication of $B$. abortus (Fig. 6). These compounds are known for their anticancer properties, but their anti-infective properties were not previously reported.

The Warburg shift in host metabolism upon pathogen infection is a welldocumented effect. For example, Mycobacterium tuberculosis enhances glycolysis in THP-1 cells (36). Early studies of infection-induced changes in host metabolism showed that cells infected with Chlamydia increase the utilization of glucose through glycolysis and increase lactate production (37). Other pathogens, including the parasite Plasmodium falciparum (38), and Mayaro virus (39), induce similar changes in host metabolism. Given these results, it is unlikely that the changes observed in our study are specifically induced by $B$. abortus. This is supported by our observation that lactate production is induced upon exposure to heat-killed B. abortus (Fig. 4A).

The relevance of a Brucella-induced increase in aerobic glycolysis and lactate production to in vivo infection biology in natural hosts remains unclear. The importance of $B$. abortus glycolysis in infection is supported by data showing that the deletion of pyruvate kinase, which presumably renders the strain unable to execute the last step of glycolysis, results in attenuation in macrophage and mouse infection models (40). However, this mutation is pleiotropic and may result in attenuation for a variety of 


\section{A Uninfected macrophage}

Glucose

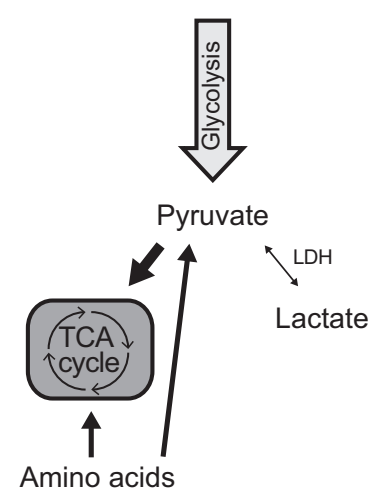

Infected macrophage

Glucose

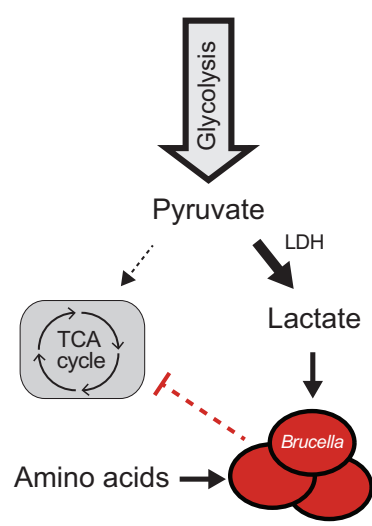

FIG 7 Model of how B. abortus may exploit a shift to Warburg-like metabolism in host cells. Data presented in this study support a model in which inhibition of tricarboxylic acid (TCA) cycle metabolism upon infection biases the host cell away from amino acid catabolism and toward the production of lactic acid. (A) Uninfected macrophages exhibit typical central carbon metabolism in which pyruvate enters the TCA cycle. (B) B. abortus infection biases the macrophage toward aerobic glycolysis and lactate production and decreased amino acid catabolism. B. abortus can utilize select amino acids as carbon and energy substrates and can also utilize lactic acid via the lactate dehydrogenase (LDH) enzyme LIdD. A strain lacking $I I d D$ is compromised in lactic acid metabolism in axenic culture and in intracellular survival in a THP-1 macrophage model. Pharmacological inhibition of host glycolysis or LDH-A reduces B. abortus survival in the intracellular niche in a THP-1 infection model.

reasons. While classically activated M1 macrophages undergo a shift to Warburg-like metabolism upon exposure to pathogen-associated molecular patterns (PAMPs), Xavier and colleagues have shown that $B$. abortus preferentially infects alternatively activated M2 macrophages in mice, which have an opposite metabolic profile, showing decreased aerobic glycolysis (12). As recently noted $(26,33)$, the physiological characteristics of host cell types and tissues colonized by Brucella spp. during the course of disease vary significantly, and it may be that lactate catabolism is important in some in vivo microenvironments but irrelevant in others.

Collectively, the data presented in this study support a model in which intracellular B. abortus can subvert host amino acid and carbohydrate metabolic pathways to support its growth and survival in the host niche (Fig. 7). The host antimetabolic compounds identified here and in previous studies (41) may provide a novel therapeutic approach to treat $B$. abortus and other bacterial infections that rely on host metabolic intermediates.

\section{MATERIALS AND METHODS}

Bacterial strains. All studies on live B. abortus strain 2308 were conducted at biosafety level 3 (BSL-3) at the Howard Taylor Ricketts Regional Biocontainment Laboratory, University of Chicago, according to U.S. Federal Select Agent Program guidelines. B. abortus expressing mCherry was previously generated from the wild-type $B$. abortus 2308 parent strain by integrating mini-Tn7 expressing a single copy of $m$ Cherry at the glms locus. The bacterial strains used in this study are listed in Table S1.

Mammalian tissue culture. Prior to each experiment, THP-1 macrophage-like cells were grown to a maximum density of $1 \times 10^{6} \mathrm{ml}^{-1}$ in complete RPMI 1640 medium (HyClone) supplemented with $2 \mathrm{mM}$ glutamine (Gibco) and 10\% heat-inactivated fetal bovine serum (FBS) (HyClone). HeLa cells were grown in Dulbecco modified Eagle's medium (DMEM; HyClone) supplemented with $10 \%$ heat-inactivated FBS. All tissue culture cells were grown at $37^{\circ} \mathrm{C}$ in a humidified environment with $5 \% \mathrm{CO}_{2}$.

Mammalian Phenotype MicroArray. (i) Mitochondrion toxicity. THP-1 cells were seeded at 50,000 cells/well in two half-area 96 -well plates in the presence of $40 \mathrm{ng} \cdot \mathrm{ml}^{-1}$ phorbol myristate acetate (PMA) and allowed to differentiate for $72 \mathrm{~h}$ at $37^{\circ} \mathrm{C}$. One plate was infected, while the other was a noninfected control. B. abortus 2308 strain was streaked onto Schaedler blood agar (SBA) plates before growing for 2 days, restreaking, and growing for another 2 days. On the day of infection, Brucella cells were scraped off the SBA plate and suspended and washed in RPMI 1640 growth medium. Cell concentration was determined by measuring the optical density at $600 \mathrm{~nm}\left(\mathrm{OD}_{600}\right)$. For the infection plate, bacteria were added to the last column of the 96 -well plate at 1,000 MOI and serially diluted by a factor of two. The 
first column was left uninfected. Both uninfected and infected plates were centrifuged at 2,170 rpm for $10 \mathrm{~min}$, followed by a 1-h incubation at $37^{\circ} \mathrm{C}$ and $5 \% \mathrm{CO}_{2}$. Gentamicin was added to each well of both uninfected and infected plates at a final concentration of $100 \mu \mathrm{g} \cdot \mathrm{ml}^{-1}$, and the plates were further incubated for $1 \mathrm{~h}$. Following incubation, the medium was removed from both plates and replaced with fresh medium containing $25 \mu \mathrm{g} \cdot \mathrm{ml}^{-1}$ gentamicin. Cells were incubated for $24 \mathrm{~h}$. Twenty-four hours after infection, two PM-M TOX1 MicroPlates (Biolog) were reconstituted with $50 \mu \mathrm{l}$ (per well) of MC-0 medium (Biolog IF-M1 medium, $0.3 \mathrm{mM} \mathrm{L-Gln}, 5 \%$ dialyzed FBS, $25 \mu \mathrm{g} \cdot \mathrm{ml}^{-1}$ gentamicin). The culture medium was removed from infected cells and replaced with the contents of reconstituted PM-M TOX1 plates. Brucella-infected cells were incubated in the presence of mitochondrial substrates for another $24 \mathrm{~h}$. Following this incubation, $10 \mu \mathrm{l}$ of PM-A dye (Biolog) was added to each well, and the absorbance at 590 $\mathrm{nm}$ and $750 \mathrm{~nm}$ was measured every $15 \mathrm{~min}$ (up to $150 \mathrm{~min}$ ) using a Tecan Infinite 200 PRO microplate reader. Plates were incubated at $37^{\circ} \mathrm{C}$ and $5 \% \mathrm{CO}_{2}$ between readings. The collected absorbance $590 \mathrm{~nm}$ data (minus reference absorbance at $750 \mathrm{~nm}$ ) were analyzed as a function of time.

Following the experiment, cell viability was assessed by removing all liquid from the PM-M TOX1 plate, replacing it with glucose-supplemented growth medium containing $10 \% \mathrm{FBS}$ and $0.5 \mathrm{mg} \cdot \mathrm{ml}^{-1}$ MTT reagent, and then measuring the absorbance at $570 \mathrm{~nm}$ after $24 \mathrm{~h}$.

(ii) Utilization of amino acids. THP-1 and B. abortus 2308 cells were prepared as described above. The infection protocol was as described above, with small changes. Bacteria were added to differentiated THP-1 cells in a 96-well plate at $100 \mathrm{MOI}$. Plates were centrifuged at 2,170 rpm for $10 \mathrm{~min}$, followed by a 1-h incubation at $37^{\circ} \mathrm{C}$ and $5 \% \mathrm{CO}_{2}$. Gentamicin was added to each well of uninfected and infected plates at a final concentration of $100 \mu \mathrm{g} \cdot \mathrm{ml}^{-1}$, and plates were further incubated for $1 \mathrm{~h}$. Following incubation, the medium was removed from both plates and replaced with fresh medium containing 25 $\mu \mathrm{g} \cdot \mathrm{ml}^{-1}$ gentamicin. Cells were incubated for $24 \mathrm{~h}$. Twenty-four hours after infection, the content of the mammalian Phenotype MicroArray PM-M2 (Biolog) was reconstituted with $50 \mu \mathrm{l}$ (per well) of MC-0 medium (Biolog IF-M1 medium, $0.3 \mathrm{mM} \mathrm{L-Gln}, 5 \%$ dialyzed FBS, $25 \mu \mathrm{g} \cdot \mathrm{ml}^{-1}$ gentamicin). The culture medium was removed from infected cells and replaced with the contents of reconstituted PM-M2 plates. Brucella-infected cells were incubated in the presence of various amino acids for another $24 \mathrm{~h}$. Following this incubation, $10 \mu \mathrm{l}$ of dye PM-A (Biolog) was added to each well, and the absorbance at $590 \mathrm{~nm}$ and $750 \mathrm{~nm}$ was measured every $15 \mathrm{~min}$ (up to $120 \mathrm{~min}$ ) using a Tecan Infinite 200 PRO microplate reader. Plates were incubated at $37^{\circ} \mathrm{C}$ and $5 \% \mathrm{CO}_{2}$ between readings. Absorbance at $590 \mathrm{~nm}$ data (minus reference absorbance at $750 \mathrm{~nm}$ ) were analyzed as a function of time. The results were analyzed by hierarchical clustering using Gene Cluster 3.0 and visualized using Java TreeView (version 1.1.6r4).

Bacterial Phenotype MicroArray. Utilization of glucose, erythritol, and lactic acid was measured using the Phenotype MicroArray, as previously described (42). Briefly, B. abortus strains (wild type 2308 and $\triangle b a b 2$ 20315 mutant) were streaked onto an SBA plate, cultivated at $37^{\circ} \mathrm{C}$ and $5 \% \mathrm{CO}_{2}$ for $48 \mathrm{~h}$, restreaked, and grown for another $48 \mathrm{~h}$. Cells were scraped off the plate and resuspended in $1 \times \mathrm{IF}-0 \mathrm{a}$ medium (Biolog) at a final density equivalent to $5 \%$ transmittance $\left(\mathrm{OD}_{600}\right)$. Phenotype MicroArray inoculating fluids (PM1 and PM2) were prepared from 0.2- $\mu \mathrm{m}$-filtered and sterilized stock solutions at the following final concentrations: $2 \mathrm{mM} \mathrm{MgCl} 2,1 \mathrm{mM} \mathrm{CaCl}, 25 \mu \mathrm{M}$ L-arginine, $50 \mu \mathrm{M} \mathrm{L-glutamic} \mathrm{acid,} 5 \mu \mathrm{M}$ $\beta$-NAD, $25 \mu \mathrm{M}$ hypoxanthine, $25 \mu \mathrm{M}$ 5'-UMP, $25 \mu \mathrm{M}$ L-cystine (pH 8.5), 0.005\% yeast extract, and $0.005 \%$ Tween 40. PM1 and PM2 inoculating fluids were prepared in 1X IF-0a GN/GP medium (Biolog). Dye mix G (Biolog) was added to each solution to a final concentration of $1 \times$. A 1:13.6 dilution of 5\% transmittance Brucella suspension was added to each inoculating fluid. Per well, $100 \mu \mathrm{l}$ of Brucellacontaining inoculating fluid was dispensed into each plate. Phenotype MicroArray plates were incubated at $37^{\circ} \mathrm{C}$ and $5 \% \mathrm{CO}_{2}$, and the absorbance at $630 \mathrm{~nm}$ was measured every $24 \mathrm{~h}$ for up to 5 days using a Tecan Infinite 200 PRO microplate reader.

Imaging of mitochondria. HeLa cells were seeded onto 22 by $22 \mathrm{~mm}$ cover slides at 50,000 cells/well in a 6-well plate in $2 \mathrm{ml}$ of DMEM per well. Cells were grown for $24 \mathrm{~h}$ prior to infection. Prior to infection, a culture of $B$. abortus constitutively expressing mCherry was inoculated in Brucella broth and grown overnight at $37^{\circ} \mathrm{C}$ on an orbital shaker. On the day of infection, Brucella cells were collected, resuspended in DMEM, and opsonized by incubating for $30 \mathrm{~min}$ at $37^{\circ} \mathrm{C}$ with 1:1,000 dilution of serum obtained from Brucella-infected mice, as previously described (43). Following opsonization, cells were washed and added to HeLa cells at 10,000 MOI. The plate was centrifuged at 2,170 rpm for $20 \mathrm{~min}$ and placed for $24 \mathrm{~h}$ at $37^{\circ} \mathrm{C}$ and $5 \% \mathrm{CO}_{2}$. Following incubation, cells were washed with DMEM, reinfected at $10,000 \mathrm{MOI}$, and incubated for another $24 \mathrm{~h}$. After this incubation, cells were washed with DMEM, and the cover slide was transferred to a 50-ml tube containing $15 \mathrm{ml}$ of DMEM and $200 \mu \mathrm{g} \cdot \mathrm{ml}^{-1}$ gentamicin. The slide was incubated at $37^{\circ} \mathrm{C}$ and $5 \% \mathrm{CO}_{2}$ for $1 \mathrm{~h}$. Following the incubation, $15 \mu \mathrm{l} \mathrm{of} 10 \mathrm{mg} \cdot \mathrm{ml}^{-1}$ Hoechst stain and $2 \mu \mathrm{l}$ of $1 \mathrm{mM}$ MitoTracker (Molecular Probes) dye were added and incubated for another $20 \mathrm{~min}$. The cover slide was washed and placed on a microscope slide with cells facing up. A drop of DMEM was placed on top of the cover slide and covered by another 22 by $22 \mathrm{~mm}$ cover slide. To prevent medium evaporation, the edges were quickly sealed with nail polish, and live cells were immediately imaged using a Leica-DMI6000B fluorescence microscope equipped with an HC PL APO $63 \times / 1.4$ numerical aperture (NA) oil PH3 CS2 objective. Images were captured using Leica Application Suite $\mathrm{X}$ and a Hamamatsu Orca-R2 camera. To test the effect of gentamicin on mitochondrion staining, HeLa cells were treated with 0 to $200 \mu \mathrm{g} \cdot \mathrm{ml}^{-1}$ gentamicin for $24 \mathrm{~h}$ and stained as described above.

Quantification of lactic acid. Intracellular lactic acid levels were quantified according to the manufacturer's protocol using a lactate assay kit (Sigma-Aldrich). Briefly, THP-1 cells were seeded and infected with either live or heat-killed B. abortus at increasing MOl, as described above. Infected cells were incubated for $48 \mathrm{~h}$ before quantifying lactate levels. After incubation, cells were washed with phosphate-buffered saline (PBS) and homogenized in $60 \mu \mathrm{l}$ of lactate assay buffer, and cell debris was 
removed by centrifuging at $14,000 \times g$ for $10 \mathrm{~min}$. Fifty microliters of supernatant was collected from each sample, and endogenous lactate dehydrogenase was removed by centrifuging supernatants at $14,000 \times g$ for 30 min using 10-kDa molecular weight cutoff (MWCO) Ultra-0.5-ml spin filter (Amicon). Twenty microliters of lactate assay buffer was added to each sample to bring the volume up to $50 \mu$ l. Fifty microliters of master mix (lactate assay buffer, enzyme mix, and probe) was added to each well, mixed, and incubated in the dark at room temperature for $30 \mathrm{~min}$ before measuring the absorbance at $570 \mathrm{~nm}$. Lactate concentration was calculated based on a standard lactate curve and normalized to the number of cells per well. To assess the effect of heat-killed B. abortus on THP-1 lactate production, the titers of $B$. abortus cells were first determined by serial dilution. These cells were then incubated for $1 \mathrm{~h}$ at $95^{\circ} \mathrm{C}$ to heat kill.

Construction of $\boldsymbol{B}$. abortus IIdD chromosomal deletion. A chromosomal deletion of $B$. abortus IIdD (bab2_0315) was obtained using a double recombination strategy. The primers used in this study are given in Table S2. The 500 bp upstream (using primers 1775 and 1779) and downstream (using primers 1776 and 1777) of IIdD were Gibson-cloned into pNPTS138, which was digested with BamHI and HindIII (New England BioLabs). The constructs were validated by DNA sequencing. To delete IIdD, the deletion plasmid was transformed into $B$. abortus, and primary integrants were selected by plating on SBA supplemented with $50 \mu \mathrm{g} \cdot \mathrm{ml}^{-1}$ kanamycin (SBA-Kan). The resulting colonies were grown overnight in Brucella broth without selection and plated on SBA supplemented with $5 \%$ sucrose to select for second crossovers. The resulting colonies were screened for the $I I D$ deletion by sequencing using the sequencing primers $1788 / 1789$.

To complement the $I / d D$ deletion strain, the $/ I d D$ gene plus the 500 bp upstream and downstream (using primers 1775/1777) were Gibson-cloned into pNPTS138 and restored at the native site using a two-step recombination strategy, as outlined above.

Brucella axenic growth. The concentration of Brucella cells (wild-type [WT] 2308 and $\Delta b a b 2$ 20315 mutant) was adjusted to $20 \%$ transmittance at $\mathrm{OD}_{600}$ and diluted into glucose-containing Brucella broth (Difco) at 1:20. MTT [3-(4.5-dimethylthiazol-2-yl)-2.5-diphenyltetrazolium bromide] reagent was added to the medium to a final concentration of $0.5 \mathrm{mg} \cdot \mathrm{ml}^{-1}$, and cells were continuously incubated at $37^{\circ} \mathrm{C}$ in a Tecan plate reader, taking absorbance readings at $570 \mathrm{~nm}$ every 10 min for $72 \mathrm{~h}$.

Brucella axenic growth compound cytotoxicity. NHI-2 (Sigma-Aldrich), 3-BPA, and 2-dG (Santa Cruz Biotechnology) were freshly prepared and serially diluted to test concentrations in a half-area 96-well plate in a total volume of $50 \mu \mathrm{l}$ of PM9 medium $\left(2 \mathrm{mM} \mathrm{MgCl} \cdot 6 \mathrm{H}_{2} \mathrm{O}, 1 \mathrm{mM} \mathrm{CaCl} \cdot 2 \mathrm{H}_{2} \mathrm{O}\right.$, $0.005 \%$ yeast extract, $0.005 \%$ Tween $40,2.5 \mathrm{mM}$ D-glucose, $5 \mathrm{mM}$ sodium pyruvate, and $1 \times$ Dye Mix G [Biolog]). WT Brucella abortus strain 2308 was prepared from a plate culture in PM9 medium at $20 \%$ transmission at $600 \mathrm{~nm}$, and $50 \mu \mathrm{l}$ was added to each well for a total volume of $100 \mu \mathrm{l}$ per well. Cells were incubated at $37^{\circ} \mathrm{C}$, and the absorbance at $630 \mathrm{~nm}$ was read every $2 \mathrm{~h}$ for $72 \mathrm{~h}$ using a Tecan microplate reader.

XTT cell viability assay. The cytotoxicity of NHI-2, 3-BPA, and 2-dG to THP-1 cells was assessed using the XTT cell proliferation and viability assay kit (Roche), according to the supplier's protocol. Briefly, cells were seeded at 50,000 cells/well. Various concentrations of compounds were added to each well, in triplicate, in the presence of $25 \mu \mathrm{g} \cdot \mathrm{ml}^{-1}$ gentamicin. Cells were incubated for $72 \mathrm{~h}$ before measuring viability using the XTT assay. XTT reagents were prepared according to the manufacturer's instructions. Following incubation, $50 \mu \mathrm{l}$ of XTT labeling mixture was added per well, and cells were further incubated for $4 \mathrm{~h}$ at $37^{\circ} \mathrm{C}$ and $5 \% \mathrm{CO}_{2}$. Absorbance measurements were collected at $590 \mathrm{~nm}$ and $750 \mathrm{~nm}$ (reference wavelength). Final data were expressed as absorbance readings at $590 \mathrm{~nm}$ (minus $750 \mathrm{~nm}$ reference absorbance) at the respective compound concentrations.

Quantifying Brucella infection of THP-1 cells. THP-1 cells were seeded in a black-well clear-bottom 96-well plate (Costar) at 50,000 cells/well, differentiated with $40 \mathrm{ng} \cdot \mathrm{ml}^{-1}$ PMA for $72 \mathrm{~h}$. Two hours before infection, cells were treated with compounds and infected with B. abortus at $100 \mathrm{MOI}$, as described above. Fresh compounds were added back into media containing $25 \mu \mathrm{g} \cdot \mathrm{ml}^{-1}$ gentamicin, and cells were further incubated for $72 \mathrm{~h}$. After incubation, cells were washed three times with $1 \times$ PBS and fixed for $10 \mathrm{~min}$ with $4 \%$ paraformaldehyde, followed by three washes with $1 \times$ PBS. Cell nuclei were labeled with $1 \mu \mathrm{g} \cdot \mathrm{ml}^{-1}$ Hoechst stain. Cells were imaged using a Leica-DMI6000B fluorescence microscope equipped with a $20 \times / 0.4$ NA objective, Hamamatsu Orca-R2 camera, and Leica Application Suite X. Forty images were captured in four replicate experiments (10 images per condition per replicate). Cell Profiler (version 2.1.1) was used to measure the number of intracellular fluorescent brucellae and the number of THP-1 nuclei. The effects of the compounds on B. abortus intracellular growth were assessed by calculating the number of bacteria per cell, represented as a ratio of the total number of bacteria to the total number of nuclei (Brucella bacteria per THP-1 nucleus) per image, which was calculated as an average \pm standard error of the mean for 40 images. Statistical significance was determined using one-way analysis of variance (ANOVA), followed by Dunnett's test.

To enumerate CFU at 1, 24, and 48 h postinfection of THP-1, B. abortus cells were resuspended in warmed RPMI and added at a multiplicity of infection (MOI) of 100 CFU per macrophage cell. To synchronize infections after the addition of Brucella cells, plates were centrifuged at $200 \times g$ for 5 min. After a 30-min incubation, the medium was removed and replaced with RPMI supplemented with $100 \mu \mathrm{g}$ - $\mathrm{ml}^{-1}$ gentamicin to kill extracellular bacteria. Afterwards, samples were incubated for $1 \mathrm{~h}$, after which monolayers were washed with PBS and THP-1 cells were lysed by the addition of $0.1 \%$ Triton X-100. Serial dilutions were prepared, and viable cells were determined by plating on tryptic soy agar (TSA) plates. For longer time points, the RPMI was removed and replaced with RPMI supplemented with $50 \mu \mathrm{g} \cdot \mathrm{ml}^{-1}$ gentamicin. Additional samples were lysed as described above and serial dilutions plated. All THP-1 assays were performed in triplicate, utilizing independent $B$. abortus cultures. 


\section{SUPPLEMENTAL MATERIAL}

Supplemental material for this article may be found at https://doi.org/10.1128/JB

.00227-17.

SUPPLEMENTAL FILE 1, PDF file, 5.5 MB.

\section{ACKNOWLEDGMENTS}

We thank the support staff of the Howard Taylor Ricketts Regional Biocontainment Laboratory. We also thank Barry Bochner, Aretha Fiebig, and Jennifer Mach for thoughtful feedback and critical evaluation of the manuscript.

This study was funded in part by National Institutes of Health grants R01Al107159 and U19AI107792 to S.C. and the Chicago Biomedical Consortium with support from the Searle Funds at the Chicago Community Trust.

D.M.C. and S.C. conceived and designed the experiments, analyzed the data, and wrote the manuscript. D.M.C. and J.W.W. performed the experiments. All authors reviewed and approved the final manuscript.

\section{REFERENCES}

1. Galván-Peña S, O'Neill LAJ. 2014. Metabolic reprograming in macrophage polarization. Front Immunol 5:420. https://doi.org/10.3389/fimmu .2014.00420.

2. Pearce EL, Pearce EJ. 2013. Metabolic pathways in immune cell activation and quiescence. Immunity 38:633-643. https://doi.org/10.1016/j immuni.2013.04.005.

3. Kelly B, O'Neill LA. 2015. Metabolic reprogramming in macrophages and dendritic cells in innate immunity. Cell Res 25:771-784. https://doi.org/ 10.1038/cr.2015.68.

4. Warburg O, Wind F, Negelein E. 1927. The metabolism of tumors in the body. J Gen Physiol 8:519-530. https://doi.org/10.1085/jgp.8.6.519.

5. Bedard K, Krause KH. 2007. The NOX family of ROS-generating NADPH oxidases: physiology and pathophysiology. Physiol Rev 87:245-313. https://doi.org/10.1152/physrev.00044.2005.

6. Nathan CF, Hibbs JB, Jr. 1991. Role of nitric oxide synthesis in macrophage antimicrobial activity. Curr Opin Immunol 3:65-70. https://doi .org/10.1016/0952-7915(91)90079-G.

7. Luckhart S, Pakpour N, Giulivi C. 2015. Host-pathogen interactions in malaria: cross-kingdom signaling and mitochondrial regulation. Curr Opin Immunol 36:73-79. https://doi.org/10.1016/j.coi.2015.07.002.

8. Koshiba T. 2013. Mitochondrial-mediated antiviral immunity. Biochim Biophys Acta 1833:225-232. https://doi.org/10.1016/j.bbamcr.2012.03 .005 .

9. Li T, Xu Y, Liu L, Huang M, Wang Z, Tong Z, Zhang H, Guo F, Chen C. 2016. Brucella melitensis $16 \mathrm{M}$ regulates the effect of AIR domain on inflammatory factors, autophagy, and apoptosis in mouse macrophage through the ROS signaling pathway. PLoS One 11:e0167486. https://doi .org/10.1371/journal.pone.0167486.

10. Stavru F, Bouillaud F, Sartori A, Ricquier D, Cossart P. 2011. Listeria monocytogenes transiently alters mitochondrial dynamics during infection. Proc Natl Acad Sci U S A 108:3612-3617. https://doi.org/10.1073/ pnas. 1100126108.

11. Owen OE, Kalhan SC, Hanson RW. 2002. The key role of anaplerosis and cataplerosis for citric acid cycle function. J Biol Chem 277:30409-30412. https://doi.org/10.1074/jbc.R200006200.

12. Xavier MN, Winter MG, Spees AM, den Hartigh AB, Nguyen $K$, Roux $C M$, Silva TMA, Atluri VL, Kerrinnes T, Keestra AM, Monack DM, Luciw PA, Eigenheer RA, Bäumler AJ, Santos RL, Tsolis RM. 2013. PPAR $\gamma$-mediated increase in glucose availability sustains chronic Brucella abortus infection in alternatively activated macrophages. Cell Host Microbe 14:159-170. https://doi.org/10.1016/j.chom.2013.07.009.

13. Roop RM, Jr, Caswell CC. 2013. Bacterial persistence: finding the "sweet spot." Cell Host Microbe 14:119-120. https://doi.org/10.1016/j.chom 2013.07.016.

14. Eisele NA, Ruby T, Jacobson A, Manzanillo PS, Cox JS, Lam L, Mukundan L, Chawla A, Monack DM. 2013. Salmonella require the fatty acid regulator PPAR $\delta$ for the establishment of a metabolic environment essential for long-term persistence. Cell Host Microbe 14:171-182. https://doi.org/ 10.1016/j.chom.2013.07.010.

15. Cardaci S, Desideri E, Ciriolo MR. 2012. Targeting aerobic glycolysis: 3-bromopyruvate as a promising anticancer drug. J Bioenerg Biomembr 44:17-29. https://doi.org/10.1007/s10863-012-9422-7.

16. Ko YH, Smith BL, Wang Y, Pomper MG, Rini DA, Torbenson MS, Hullihen J, Pedersen PL. 2004. Advanced cancers: eradication in all cases using 3-bromopyruvate therapy to deplete ATP. Biochem Biophys Res Commun 324:269-275. https://doi.org/10.1016/j.bbrc.2004.09.047.

17. Calvaresi EC, Granchi C, Tuccinardi T, Di Bussolo V, Huigens RW, III, Lee HY, Palchaudhuri R, Macchia M, Martinelli A, Minutolo F, Hergenrother PJ. 2013. Dual targeting of the Warburg effect with a glucose-conjugated lactate dehydrogenase inhibitor. Chembiochem 14:2263-2267. https://doi.org/10 .1002/cbic.201300562.

18. Wick AN, Drury DR, Nakada HI, Wolfe JB. 1957. Localization of the primary metabolic block produced by 2-deoxyglucose. J Biol Chem 224:963-969.

19. Bochner BR, Siri M, Huang RH, Noble S, Lei XH, Clemons PA, Wagner BK. 2011. Assay of the multiple energy-producing pathways of mammalian cells. PLoS One 6:e18147. https://doi.org/10.1371/journal.pone.0018147.

20. He Y, Reichow S, Ramamoorthy S, Ding X, Lathigra R, Craig JC, Sobral BW, Schurig GG, Sriranganathan N, Boyle SM. 2006. Brucella melitensis triggers time-dependent modulation of apoptosis and down-regulation of mitochondrion-associated gene expression in mouse macrophages. Infect Immun 74:5035-5046. https://doi.org/10.1128/IAI.01998-05.

21. Lobet E, Letesson JJ, Arnould T. 2015. Mitochondria: a target for bacteria. Biochem Pharmacol 94:173-185. https://doi.org/10.1016/j.bcp.2015.02 .007 .

22. Ma C, Wickham ME, Guttman JA, Deng W, Walker J, Madsen $\mathrm{KL}$, Jacobson $\mathrm{K}$, Vogl WA, Finlay BB, Vallance BA. 2006. Citrobacter rodentium infection causes both mitochondrial dysfunction and intestinal epithelial barrier disruption in vivo: role of mitochondrial associated protein (Map). Cell Microbiol 8:1669-1686. https://doi.org/10.1111/j.1462-5822.2006.00741.x.

23. Lyamzaev KG, Pletjushkina OY, Saprunova VB, Bakeeva LE, Chernyak BV, Skulachev VP. 2004. Selective elimination of mitochondria from living cells induced by inhibitors of bioenergetic functions. Biochem Soc Trans 32:1070-1071. https://doi.org/10.1042/BST0321070.

24. Abu Kwaik Y, Bumann D. 2015. Host delivery of favorite meals for intracellular pathogens. PLoS Pathog 11:e1004866. https://doi.org/10 .1371/journal.ppat.1004866.

25. Lamontagne J, Forest A, Marazzo E, Denis F, Butler $H$, Michaud JF, Boucher L, Pedro I, Villeneuve A, Sitnikov D, Trudel K, Nassif N, Boudjelti D, Tomaki F, Chaves-Olarte E, Guzman-Verri C, Brunet S, Cote-Martin A Hunter J, Moreno E, Paramithiotis E. 2009. Intracellular adaptation of Brucella abortus. J Proteome Res 8:1594-1609. https://doi.org/10.1021/ pr800978p.

26. Zúñiga-Ripa A, Barbier T, Conde-Alvarez R, Martinez-Gomez E, PalaciosChaves L, Gil-Ramirez Y, Grillo MJ, Letesson JJ, Iriarte M, Moriyon I. 2014. Brucella abortus depends on pyruvate phosphate dikinase and malic enzyme but not on Fbp and GlpX fructose-1,6-bisphosphatases for full virulence in laboratory models. J Bacteriol 196:3045-3057. https://doi .org/10.1128/JB.01663-14.

27. Anderson JD, Smith H. 1965. The metabolism of erythritol by Brucella 
abortus. J Gen Microbiol 38:109-124. https://doi.org/10.1099/00221287 -38-1-109.

28. Gerhardt P, Tucker LA, Wilson JB. 1950. The nutrition of brucellae: utilization of single amino acids for growth. J Bacteriol 59:777-782.

29. Gerhardt P, Wilson JB. 1948. The nutrition of brucellae: growth in simple chemically defined media. J Bacteriol 56:17-24.

30. Battaglia FC, Meschia G. 1978. Principal substrates of fetal metabolism. Physiol Rev 58:499-527.

31. Goldberg E, Eddy EM, Duan C, Odet F. 2010. LDHC: the ultimate testisspecific gene. J Androl 31:86-94. https://doi.org/10.2164/jandrol.109 .008367.

32. Eisenreich W, Dandekar T, Heesemann J, Goebel W. 2010. Carbon metabolism of intracellular bacterial pathogens and possible links to virulence. Nat Rev Microbiol 8:401-412. https://doi.org/10.1038/nrmicro2351.

33. Letesson JJ, Barbier T, Zuniga-Ripa A, Godfroid J, De Bolle X, Moriyon I. 2017. Brucella genital tropism: what's on the menu. Front Microbiol 8:506. https:// doi.org/10.3389/fmicb.2017.00506.

34. El Sayed SM, El-Magd RM, Shishido Y, Chung SP, Diem TH, Sakai T, Watanabe H, Kagami S, Fukui K. 2012. 3-Bromopyruvate antagonizes effects of lactate and pyruvate, synergizes with citrate and exerts novel anti-glioma effects. J Bioenerg Biomembr 44:61-79. https://doi.org/10 .1007/s10863-012-9409-4.

35. Barban S, Schulze HO. 1961. The effects of 2-deoxyglucose on the growth and metabolism of cultured human cells. J Biol Chem 236: 1887-1890.

36. Mehrotra $P$, Jamwal SV, Saquib N, Sinha N, Siddiqui Z, Manivel V, Chatterjee S, Rao KV. 2014. Pathogenicity of Mycobacterium tuberculosis is expressed by regulating metabolic thresholds of the host macrophage. PLoS Pathog 10:e1004265. https://doi.org/10.1371/journal.ppat .1004265 .

37. Moulder JW. 1970. Glucose metabolism of $L$ cells before and after infection with Chlamydia psittaci. J Bacteriol 104:1189-1196.

38. Mehta M, Sonawat HM, Sharma S. 2005. Malaria parasite-infected erythrocytes inhibit glucose utilization in uninfected red cells. FEBS Lett 579:6151-6158. https://doi.org/10.1016/j.febslet.2005.09.088.

39. El-Bacha T, Menezes MMT, Azevedo e Silva MC, Sola-Penna M, Da Poian AT. 2004. Mayaro virus infection alters glucose metabolism in cultured cells through activation of the enzyme 6-phosphofructo 1-kinase. Mol Cell Biochem 266:191-198. https://doi.org/10.1023/B:MCBI.0000049154 .17866 .00 .

40. Gao J, Tian M, Bao Y, Li P, Liu J, Ding C, Wang S, Li T, Yu S. 2016. Pyruvate kinase is necessary for Brucella abortus full virulence in BALB/c mouse. Vet Res 47:87. https://doi.org/10.1186/s13567-016-0372-7.

41. Czyż DM, Jain-Gupta N, Shuman HA, Crosson S. 2016. A dual-targeting approach to inhibit Brucella abortus replication in human cells. Sci Rep 6:35835. https://doi.org/10.1038/srep35835.

42. Herrou J, Czyż DM, Willett JW, Kim HS, Chhor G, Babnigg G, Kim Y, Crosson S. 2016. WrpA is an atypical flavodoxin family protein under regulatory control of the Brucella abortus general stress response system. J Bacteriol 198:1281-1293. https://doi.org/10.1128/JB.00982-15.

43. Kim HS, Caswell CC, Foreman R, Roop RM, Jr, Crosson S. 2013. The Brucella abortus general stress response system regulates chronic mammalian infection and is controlled by phosphorylation and proteolysis. $J$ Biol Chem 288:13906-13916. https://doi.org/10.1074/jbc.M113.459305. 